\title{
The processing of affixed words
}

\author{
LEON MANELIS and DAVID A. THARP \\ Illinois State University, Normal, Illinois 61761
}

\begin{abstract}
Two experiments are reported which suggest that affixed words are not morphologically decomposed but are processed as single units. Experiment 1 involved a lexical decision task, and it suggested that lexical access does not require decomposition. Experiment 2 involved a task designed to maximize the opportunity for decomposition, but it showed that subjects processed the test items as single units. These results are discussed in relation to other evidence that has been offered to support the occurrence of morphological decomposition.
\end{abstract}

The topic of this paper is the recognition of affixed words. The words investigated here are separable into two morphemes: a free morpheme base form (e.g., DARK) and a suffix (e.g., -ER). There are two basic alternative hypotheses. According to the single unit hypothesis, each affixed word would be stored in the lexicon as a separate entry and accessing that entry would be sufficient to recognize the word. Because each affixed variant of a base would require a separate entry, this system would require a large amount of storage; but because each word would be recognized as a single unit, there could be an economy in processing. According to the decomposition hypothesis, on the other hand, the words would be recognized by analyzing them into two units, base forms and affixes. This system would allow an economy of storage because all the variants of a base form would not have to be represented separately. Instead, the base form could be represented only once. In order to recognize a word that has an affix, the base form would be accessed and then the affix would be combined with it. More specific descriptions of the decomposition hypothesis, as well as the single unit hypothesis, will be discussed below.

There have been other studies that have touched on the issue of decomposition. Murrell and Morton (1974) had subjects memorize lists of words prior to a tachistoscopic recognition task. Some of the memorized words had the same base forms as the test words, and the similarity facilitated recognition. Kintsch (1972) tested morphologically simple words vs. morphologically complex words in paired associate learning and found that complexity impaired learning. Both of these studies, however, involved memory for lists learned in the experimental context [Tulving's (1972) "episodic memory"] rather than direct access

This research was supported in part by Grant MH28068 from the National Institute of Mental Health to L. Manelis. The authors thank Kenneth I. Forster for his very helpful comments on a preliminary version of this paper and for making available a preprint of relevant work with Marcus Taft. Requests for reprints should be sent to L. Manelis, Department of Psychology, Illinois State University, Normal, Illinois 61761. to the internal lexicon ("semantic memory"). Gibson and Guinet (1971) claim that inflected endings (e.g., -ING) are reported more accurately than endings of noninflected words. However, their study used a free report task. This type task is open to guessing biases, and inflections are likely to be guessed because they are common endings of words, even disregarding their functions as inflections. Kintsch (1974, Chapter 11) reports several experiments investigating the decomposition of words, although his emphasis is on semantic analysis (e.g., KILL is analyzed as CAUSE TO DIE), rather than the syntactic or derivational role of affixes. Holyoak, Glass, and Mah (1976) investigated decomposition, although like Kintsch (1974), in the context of a comprehension task rather than the recognition of individual words. Finally, MacKay (1976) investigated the production of past tense verbs when subjects were given the present tense forms. All of these studies are indirectly related to the present one but do not provide direct evidence on the recognition of individual words in the internal lexicon. More directly related work is reported by Taft and Forster (1975), whose results will be discussed below in comparison with those from the present study.

Two experiments are reported here. In Experiment 1, affixed words were compared with closely matched nonaffixed words which contained the same endings. These items were tested in a lexical decision task which required subjects to access the words in the internal lexicon. The results suggested that lexical access does not require decomposition. Experiment 2 involved a task designed to maximize the opportunity for decomposition but produced results predicted by the single unit hypothesis.

\section{EXPERIMENT 1}

The main comparison in this experiment was between lexical decision times for affixed and nonaffixed words. The nonaffixed words were specially selected in order to avoid a potential problem. Because affixes are used very commonly in words, it is possible that the reaction time for an affixed word would be affected by the 
presence of the common ending alone, regardless of its grammatical function. Thus, in order to match the affixed words, the nonaffixed words were selected to have the same endings. For example, the word SISTER contains the ending -ER which does not function as an affix.

Our hypotheses about the ways that these words could be recognized are diagramed in Table 1 . According to the decomposition-first hypothesis, the word w'ould initially be decomposed into base and affix. A test would then be performed to determine whether the base and affix are valid as a combination. How this step might proceed is not important to the present discussion, but we can offer one possibility. In the case of MELTING, for example, the lexical entry for the base MELT might be accessed and the information that MELT is a regular verb could be retrieved. The rule that regular verbs can take -ING as endings would be applied, and thus the complete word would be found acceptable. If the word is not affixed, it would be decomposed anyway because of the presence of an ending that can serve as an affix, but the word would be found an invalid combination at Step 2. A lexical search for the word as a whole would then be performed at Step 3, and a positive response would be made. Because of the extra step needed for the nonaffixed words, according to the decomposition-first hypothesis, they would be predicted to produce longer reaction times than the affixed words.

The decomposition-second hypothesis also involves decomposition, but the order of processing is different: The lexical search for the whole item is performed at Step 1. A nonaffixed word would immediately yield a positive response. But if the word is affixed, then

Table 1

Altemative Processes for Affixed and Nonaffixed Words

Decomposition First

Step 1 Decompose whole item into base and ending.

Step 2 Test whether base and ending are valid in combination as affixed word.

If yes, give positive response.

If no, do Step 3.

Step 3 Search lexicon for whole item. If present, give positive response. If absent, give negative response.

Decomposition Second

Step 1 Search lexicon for whole item. If present, give positive response. If absent, do Steps 2 and 3.

Step 2 Decompose whole item into base and ending.

Step 3 Test whether base and ending are valid in combination as affixed word.

If yes, give positive response.

If no, give negative response.

Single Unit Hypothesis

Step 1 Search lexicon for whole item. If present, give positive response. If absent, give negative response. according to the hypothesis, it would not be stored as a single unit, the lexical search would fail, and further processing would be necessary. The whole word would be decomposed at Step 2 and the combination would be tested at Step 3. Because affixed words would require extra processing, the decomposition-second hypothesis predicts a difference in the opposite direction from the decomposition-first hypothesis: Affixed words should produce slower reaction times than nonaffixed words.

The remaining alternative is the single unit hypothesis, which states that all words, whether affixed or not, are represented as separate entries in the lexicon, and they are accessed without decomposition. Unlike the previous hypotheses, this one predicts no difference between affixed and nonaffixed words.

Predictions are thus made for reaction times to each type of word. In the present experiment, pairs of items were presented on each trial, and the subjects were to make a positive response only if both items were words. For those trials on which a positive response was correct, sometimes both items were affixed words or both were nonaffixed. In these cases, any difference in reaction time for the two types of words should be exaggerated by the need to process two words on each trial. In other cases, however, the two words on a trial were of different types. These trials were included in order to detect a possible transfer effect. It may be that after processing a word of one type as the first member of a pair, subjects bias their processing to facilitate processing a word of the same type as the second member. For example, if the first member is DARKER, subjects may be biased toward decomposing a second member, SOMBER, and attempt to recognize it as "more somb." Thus, reaction time for a pair of words of different types would be greater than for pairs of the same type. Transfer effects between word pairs have been obtained in other lexical decision experiments (e.g., Meyer \& Schvaneveldt, 1971). In the present experiment, a transfer effect as described above could occur if affixed and nonaffixed words are processed differently.

\section{Method}

Stimuli and design. The words were selected in sets of four. In each set, there were two affixed words and two nonaffixed words, all having the same ending and the same number of letters. The endings used were -Y, -ING, -EST, -EN, and -ER. The words ranged in length from five to seven letters, although all contained two syllables. The items within each set were also matched as closely as possible for pattern of consonants and vowels, frequency, and part of speech. There were 15 sets of words altogether. An example is FANCY, NASTY, BULKY, DUSTY. (The Appendix lists all the stimuli.)

There were four conditions defined by the pairing of the words. In two conditions, one affixed and one nonaffixed word were presented. Denoting a nonaffixed word by " 1 " (one morpheme) and an affixed word by "2" (two morphemes), these "mixed" conditions will be called Condition 1-2 (nonaffixed word viewed first) and Condition 2-1 (affixed word viewed first). The unmixed conditions were Condition 1-1 and Condition 2-2. Each subject was tested with each item set 
in each condition. Each individual word was presented to a subject twice as a part of different conditions, although a word was never presented twice in the same block of 60 trials. The assignment of words within a set to the various conditions was counterbalanced across subjects so that all allowable pairings of words were presented equally often.

For the trials on which two words were presented, a positive response was correct. When one of the items of a pair was a nonword, a negative response was correct. For all such negative trials, only one member of the pair was a nonword; on half of the trials it was the first item viewed and on the other half it was the second item viewed. The nonwords had the same endings and the same numbers of letters as the words. The nonwords were selected in sets of three, matched to each other for ending, number of letters, and pattern of consonants and vowels. Within each set, the nonwords differed according to the nature of the letters before the ending. In Condition $W$, those letters comprised a word, as in DESKER. In Condition F, the preceding letters comprised an initial fragment of a word, as in GARMER (based on GARMENT). Condition C was a control; the preceding letters comprised neither a word nor an initial fragment, as in LOCTER. There were 10 sets of nonwords altogether. Three filler words of the same types as in the word conditions (but different from those used in the word conditions) were matched to the three nonwords in each set for ending, length, and pattern of consonants and vowels. The pairing of words and nonwords in each set was varied across subjects so that each word was paired with each nonword equally often. Each subject was presented with each nonword twice, once with its corresponding word viewed first and once with that same word second; the two presentations were in separate blocks of 60 trials.

Materials and equipment. The stimuli were typed on blank cards. One nember of a pair was above the other, and the two were separated so that both could not be easily identified in the same fixation. The cards were presented in a Scientific Prototype two-field tachistoscope, and reaction time was mcisured with a Hunter Klockounter.

Procedure. At the outset of each trial, subjects viewed a tixation field and rested each index finger on a button, one for positive responses and another for negative responses. (Assignment of preferred hand to positive and negative responses was counterbalanced across subjects.) After a signal from the experimenter, subjects pressed a foot switch that turned off the fixation field, turned on the stimulus field, and started the timer. Subjects were instructed to view the top item of each pair first and to give a positive response only if both items were words, responding as quickly as possible without making errors. When a response was made, the stimulus field went off, the timer stopped, and the fixation field came on.

There were 120 test trials, 60 positive and 60 negative trials randomly intermixed. In addition, there were 40 warm-up trials which preceded the test trials and consisted of presentations of the same type.

Subjects. Twenty-four psychology students served as subjects in exchange for course credit. Each subject served for one session of about $45 \mathrm{~min}$.

Results and Discussion

The reaction times for correct responses and the error rates are shown in Table 2 . In order to reduce the positive skewness of the reaction times, they were converted to logs; the figures in Table 2 are geometric means, antilogs of the mean logs. Statistical significance was assessed in both Experiments 1 and 2 by computing $\min F^{\prime}$, a statistic that is based on separate analyses of variance treating subjects and items as random effects and which is intended to allow generalization across both types of population within the constraints of selection (Clark, 1973; Winer, 1971). All statistical findings (significance or nonsignificance) in the min $F^{\prime}$ analyses were the same as those in the separate analyses.

For the positive responses, there were no significant differences in numbers of errors $(p>.10)$. In terms of reaction time, the mixed Conditions $2-1$ and $1-2$ were slower than the unmixed Conditions $1-1$ and $2-2$ $\left[\min F^{\prime}(1,94)=4.96, p<.05\right]$. This is evidence of a transfer effect, which suggests that the affixed and nonaffixed words were processed differently. However, there was no significant difference between Conditions $1-1$ and $2-2\left(\min F^{\prime}<1\right)$. This finding is consistent with the single unit hypothesis and inconsistent with both of the decomposition hypotheses. The finding of a transfer effect can be reconciled with the single unit hypothesis in the following way. After a word has been recognized, its meaning becomes available and influences retrieval of a subsequent word. It is known that retrieval for a pair of words is faster if they are semantically related than if they are unrelated (e.g., Meyer \& Schvaneveldt, 1971). In the present experiment, part of the meaning of the words depends on whether they are affixed or not. For example, part of the meaning of DARKER is that it is comparative. In general, affixed or nonaffixed words would share components of meaning with words of the same type but would not be so closely related to words of the other type. Thus, even though decomposition apparently does not occur and the words are retrieved as single units, a transfer effect is possible simply on the basis of the meaning of the words.

For the negative responses, the control Condition $\mathrm{C}$ produced faster reaction time than Conditions $W$ and $F$ $\left[\min F^{\prime}(1,35)=5.53, p<.05\right]$. The error rate was also significantly lower $\left[\min \mathrm{F}^{\prime}(1,35)=6.04, \mathrm{p}<.05\right]$. Conditions $W$ and $F$ did not differ significantly in reaction time or error rate (min $\left.F^{\prime} s<1\right)$. These results suggest that components within an item do affect recognition. This issue will be considered in the General Discussion.

Table 2

Results of Experiment 1

\begin{tabular}{|c|c|c|c|c|c|c|c|}
\hline & \multicolumn{4}{|c|}{ Positive Responses } & \multicolumn{3}{|c|}{ Negative Responses } \\
\hline & \multicolumn{4}{|c|}{ Condition } & \multicolumn{3}{|c|}{ Condition } \\
\hline & $2-1$ & $1-2$ & $1-1$ & $2-2$ & $\mathrm{C}$ & w & F \\
\hline $\begin{array}{l}\text { Reaction Time } \\
\text { Error Rate }\end{array}$ & $\begin{array}{l}1398 \\
(.064)\end{array}$ & $\begin{array}{l}1380 \\
(.038)\end{array}$ & $\begin{array}{l}1363 \\
(.036)\end{array}$ & $\begin{array}{l}1342 \\
(.064)\end{array}$ & $\begin{array}{l}1439 \\
(.038)\end{array}$ & $\begin{array}{l}1555 \\
(.131)\end{array}$ & $\begin{array}{l}1517 \\
(.098)\end{array}$ \\
\hline
\end{tabular}




\section{EXPERIMENT 2}

The previous experiment was consistent with the single unit hypothesis, but it rested on the finding of no difference between Conditions $1-1$ and 2-2. The second experiment was designed to provide an opportunity for the single unit hypothesis to be tested in a more positive way. Subjects in this experiment were asked to perform a matching task. At the outset of a trial, they were given a target word (e.g., SNOW) that could serve as a base form in an affixed word. They were then shown a test item that either contained the base or did not, and they were to press one of two buttons to indicate whether the base was present. The dependent measure was reaction time. The most important comparison was the nature of the test item. On some trials it was a valid affixed word (e.g., SNOWED or SLOWED), and on the other trials it was a nonword which differed from the affixed word only in that the ending made an invalid combination with the base (e.g., SNOWEN, SLOWEN). The correct response, however, depended only on the base, not the ending, and subjects were told this. Thus, the task was designed to allow subjects to decompose the test item and respond only to the base that was in it. If subjects did this, then there would be no difference in reaction time between word and nonword test items. On the other hand, if subjects processed the test item as a single unit, then the word and nonword test items could be expected to produce a difference. In particular, subjects could be expected to search the lexicon for the complete test item. If the item was found, then the identity of the base could be retrieved from the entry for the complete item and matched to the target, thus allowing the correct response to be determined. If the item was not found in the Iexicon (in the case of the nonwords), then an alternate process would be necessary. The alternate process would be some form of decomposition, forced by the requirements of the task. It is known from lexical decision studies that the time for accessing a word in the lexicon is generally less than the time for determining that a regular, pronounceable nonword is not in the lexicon (e.g., Novik, 1974). Accordingly, it is likely that, in the present experiment, if subjects do process the test items as single units, word test items should produce faster reaction times than nonword test items.

\section{Method}

Design. The experiment followed a 2 by 2 factorial design. One independent variable was the nature of the test item, word or nonword. The other independent variable was the type of response, positive or negative, determined by whether or not a target was contained in the test item. The design is illustrated in Table 3, and a sample test item from each condition is shown for the target SNOW.

Stimuli. All of the stimuli are listed in the Appendix. Each test item consisted of a free morpheme base combined with an ending. All of the base words were four letters long. The
Table 3

Design and Results of Experiment 2

\begin{tabular}{ccc} 
Type of & \multicolumn{2}{c}{ Type of Test Item } \\
\cline { 3 - 3 } Response & Word & Nonword \\
\hline Positive & SNOWED & SNOWEN \\
Reaction Time & 873 & 932 \\
Error Rate & $(.033)$ & $(.045)$ \\
Negative & SLOWED & SLOWEN \\
Reaction Time & 910 & 932 \\
Error Rate & $(.033)$ & $(.024)$ \\
\hline
\end{tabular}

endings in the test items were $-Y,-L Y,-E N,-E S,-E D,-E R$, and -ING. The test items were selected in sets of four. Within each set, there were two words and two nonwords. The two words were acceptable combinations of bases and endings and differed from each other at a single letter position in the base (e.g., SNOWED, SLOWED). The two nonwords incorporated the same bases but a different ending which could not validly combine with the bases (e.g., SNOWEN, SLOWEN). There were 48 sets of test items altogether; the contrasting letter position for the two words or nonwords in a set varied across different groups of 12 sets. The base word actually contained in a test item was the target for a positive trial (e.g., target, SNOW; test item, SNOWED). The contrasting base word was the target for a negative trial (e.g., target, SLOW; test item, SNOWED).

Counterbalancing. Each subject, each set of test items, and each target were tested under all conditions of the basic 2 by 2 design. For each subject, half of the 48 sets of test items were presented on positive trials and the other half on negative trials; one word and one nonword were presented from each set. The particular word and nonword tested on positive trials for half the subjects were presented on negative trials for the other half.

Each subject was presented with four blocks of 24 test trials. Stimuli were randomly assigned to blocks, except for the constraint that the word and nonword presented to a subject from an item set were separated from each other by one intervening block. Order of presentation of blocks was counterbalanced across subjects.

Equipment. Test items were typed in capital letters on blank cards and were displayed in an Iconix tachistoscope; reaction times were taken from the associated Iconix timing equipment. Targets were also typed on blank cards but were presented outside the tachistoscope. The response apparatus consisted of two buttons on the table directly in front of the subjects. The assignment of the subject's preferred hand to positive and negative response buttons was counterbalanced across different subjects.

Procedure. A trial began with a verbal signal from the experimenter. The subject then turned over a card to expose the target and gave a ready signal. The experimenter then pressed a button which turned on a fixation field containing two horizontal lines. After $5 \mathrm{sec}$, the fixation field went off and the test item appeared, centered in the area that had been bounded by the two lines. The subject decided whether the target was present in the test item and made a positive or negative response by pressing one of the two buttons. Subjects were instructed to respond as quickly as possible, consistent with making few errors.

For each subject there were four blocks of 24 test trials. Preceding the test trials there were 16 warm-up trials involving stimuli different from the test trials but of the same general types.

Subjects. Twenty-four people who were at least 17 years of age served as subjects in response to a newspaper advertisement. 
They received pay or course credit in return for their participation. Each subject served for one session of about $45 \mathrm{~min}$.

\section{Results and Discussion}

For each of the conditions, Table 3 shows the geometric mean reaction times for correct responses and the error rates. There were no significant effects for the error rates $(p>.10)$. The overall difference in reaction time between words and nonwords was significant [min $\left.F^{\prime}(1,69)=8.00, p<.01\right]$. Neither the effect of response type nor the interaction between type of response and type of test item was significant $\left[\min F^{\prime}<1\right.$, and $\min F^{\prime}(1,62)=1.86, \quad p>.10$, respectively]. These results indicate that subjects did process the test items as single units; they could not decompose the test items and process the bases alone, even though only the bases were relevant for deciding on the correct responses. The results are surprising in light of certain findings from studies of tachistoscopic word perception (e.g., Estes, 1975a, 1975b). There are numerous demonstrations of the superior perceptibility of a letter in the context of a word, compared with a letter in the context of a nonword. However, when subjects are presented with a small set of alternative letters prior to a tachistoscopic display, and the subjects are asked to detect the presence of one of those letters in the display, the linguistic context has no effect. In the present experiment, subjects were also asked to detect the presence of a previously presented target, but the linguistic context in the display did have an effect. A relevant difference between the two types of experiment inay be the nature of the targets. Perhaps, whenever the target consists of several letters and subjects must operate on a large proportion of the display, word recognition processes are automatically triggered.

\section{GENERAL DISCUSSION}

The purpose of this study was to investigate the way that affixed words are recognized in the internal lexicon. According to the decomposition hypothesis, they are recognized by combining a base and an affix. This hypothesis failed to be supported by the results of Experiment 1. According to the single unit hypothesis, affixed words are processed as complete wholes, without the need for decomposition. This hypothesis agrees with the results of Experiment 2.

The present study is directly related to the study of Taft and Forster (1975). Their results comprise the most direct evidence for morphological decomposition that has yet been presented. They conducted three lexical decision experiments involving bases or "stems" of prefixed words. Such "real stems" were matched to other items which were not real stems. For example, one real stem was SULTS, as in INSULTS, and the matched item was NINGS, from INNINGS. The real stem items produced longer reaction times than the matched items. The interpretation was that real stems are in fact present in the lexicon as separate entries; the extra time necessary to respond to them is caused by finding them in the lexicon and determining that because they are stems, they cannot stand alone as words.

A major difference between the Taft and Forster (1975) study and the present one is that they used words with prefixes, whereas we used words with suffixes. Very recent work by Taft and Forster (in press) implies that in lexical search, a word is processed from left to right. Thus, the presence of a prefix could trigger a morphological process even if the suffix does not.

Nevertheless, we still find a difficulty with Taft and Forster's (1975) original results. The difficulty is in the way that real stems were matched to the other items for frequency. The frequency assigned to each item was the frequency of one word from which the item was drawn. Thus, for example, SULTS was matched to NINGS on the basis of the similar frequencies for INSULTS and INNINGS, without consideration of the other words in which the real stem is contained, such as RESULTS and CONSULTS. To some extent, the same problem holds for the items other than the real stems, but on the average, the total frequency of the real stems was greater. For example, we added the frequencies for words containing the items (Kučera \& Francis, 1967) and found that in Experiment 1 of the Taft and Forster (1975) study, the mean total frequencies were 84 for real stems and 14 for the matched items; in Experiment 3, the means were 76 and 13 .

It remains to be seen whether total frequency was in fact the source of the Taft and Forster (1975) results. However, total frequency does seem a plausible alternative explanation if one assumes that higher frequency word fragments (whether or not they are morphemes) are more likely to be represented in the lexicon than lower frequency fragments. On this assumption, Taft and Forster's interpretation of their results would still apply, with the reservation that the presence of an item in the lexicon need not be determined by its morphological status. In fact, the recent work of Taft and Forster (in press) implies that the lexicon contains not only items with independent meanings (words and morphemes) but syllables as well, and that syllables are accessed in lexical retrieval. The label "single unit hypothesis," used in the present study, thus may be too strong in implying that word components are not functional. Accordingly, Experiment 1 should be interpreted to suggest that suffixed words are accessed in the same way as nonsuffixed words, although in both cases, word fragments (regardless of morphological status) may play a role. Despite these reservations, however, the term "single unit hypothesis" is appropriate and does qualify the concept of decomposition, because the results of Experiment 2 indicate that at some level of processing, word components cannot be isolated. 


\section{Appendix}

\section{Items for Experiment 1}

The item sets are separated by semicolons. For the words, each set includes two affixed words followed by two nonaffixed words. For the nonwords, each set includes items in the following order of conditions: $\mathrm{C}, \mathrm{W}, \mathrm{F}$.

Words

bulky, dusty, fancy, nasty; silky, foamy, dandy, gaudy; faulty, frosty, dainty, clumsy; tossing, hissing, cunning, pudding; fearing, melting, ceiling, sibling; lowest, newest, modest, honest; softest, fastest, contest, harvest; harden, darken, garden, burden; weaken, dampen, heaven, hyphen; renter, sorter, filter, roster; tester, sender, sister, somber; printer, drifter, slander, blister; milky, salty, candy, derby; waxen, oaken, dozen, token; charmer, spender, plaster, slumber.

Nonwords

farby, holdy, sibly; maldy, lendy, murdy; locter, desker, garmer; holking, terming, selding; sarken, facten, compen; binkest, cardest, permest; pulter, dirter, perfer; leaben, hairen, measen; brilpy, sterny, plasty; flosker, craften, scander.

\section{Items for Experiment 2}

The item sets are separated by semicolons. Each set includes two words followed by two nonwords.

marker, darker, markes, darkes; folder, holder, foldy, holdy; colder, bolder, coldy, boldy; lacking, sacking, lackest, sackest; hissing, kissing, hissen, kissen; leading, reading, leadly, readly; banding, landing, banden, landen; gained, rained, gainest, rainest; busted, dusted, busten, dusten; hinted, tinted, hintly, tintly; costly, mostly, costen, mosten; heady, beady, headest, beadest; picker, packer, pickest, packest; welder, wilder, welden, wilden; sander, sender, sandest, sendest; showing, snowing, showly, snowly; binding, bending, binden, benden; leafing, loafing, leafen, loafen; growing, glowing, growes, glowes; listed, lasted, listy, lasty; formed, farmed, formly, farmly; billed, bulled, billen, bullen; lively, lovely, livey, lovey; messy, mossy, messest, mossest; talker, tanker, talken, tanken; filmer, firmer, filmen, firmen; banker, backer, bankest, backest; seeding, sending, seeden, senden; falling, failing, fally, faily; waiting, wanting, waitly, wantly; helping, heaping, helpest, heapest; rested, rented, restest, rentest; bested, belted, besten, belten; flowed, flawed, flowly, flawly; lately, lamely, latey, lamey; handy, hardy, handes, hardes; feeler, feeder, feelen, feeden; cooler, cooker, coolen, cooken; roofer, roomer, roofly, roomly; casting, cashing, castest, cashest; looping, looting, loopen, looten; burping, burning, burply, burnly; parking, parting, parkest, partest; worded, worked, worden, worken; walked, walled, walky, wally; leaped, leaned, leapy, leany; deadly, dearly, deades, deares; wooly, woody, woolest, woodest.

\section{REFERENCES}

Clark. H. H. The language-as-fixed-effect tallacy: A critique of language statistics in psychological research.
Journal of Verbal Learning and Verbal Behavior, 1973. 12. 335-359.

Estes, W. K. The locus of inferential and perceptual processes in letter identification. Journal of Experimental Psychology: General, 1975, 104, 122-145. (a)

Estes. W. K. Memory, perception, and decision in letter identitication. In R. R. Solso (Ed.), Information processing and cognition: The Loyola symposium. Hillsdale. N.J: Erlbaum, 1975. (b)

Gibson, E. J., \& Guinet, L. Perception of inflections in brief visual presentations of words. Journal of Verbal Leaming and Verbal Behavior. 1971. 10, 182-189.

Holyoak, K. J.. Glass, A. L., \& MaH, W. A. Morphological structure and semantic retrieval. Journal of Verbul Learning and Verbal Behavior, 1976, 15, 235-247.

Kintsch, W. Abstract nouns: Imagery versus lexical complexity. Journal of Verbal Learning and Verbal Behavior, 1972, 11, 59-65.

KINTSCH. W. The representation of meaning in memory. New York: Wiley, 1974.

KuČERA, H., \& Francis, W. N. Computational analysis of present-day American English. Providence, R.I: Brown University Press. 1967.

MACKAY. D. G. On the retrieval and lexical structure of verbs. Journal of Verbal Learning and Verbal Behavior. 1976, 15, 169-182.

Meyer, D. E.. \& Schvaneveldt, R. W. Facilitation in recognizing pairs of words: Evidence of a dependence between retrieval operations. Journal of Experimental Psichologr, 1971. 90, 227-234.

Murrell, G. A., \& Morton, J. Word recognition and morphemic structure. Journal of Experimental Psychology. 1974, 102, 963-968.

Novik. N. Parallel processing in word-nonword classification 1ask. Journal of Experimental Psychology, 1974. 102. $1015-1020$.

TAFT, M.. \& Forster, K. I. Lexical storage and retrieval of pretixed words. Journal of Verbal Learning and Verbal Behavior, 1975. 14. 638-647.

TAFT. M.. \& ForSTER, K. I. Lexical storage and retrieval of polvmorphemic and polysyllabic words. Journal of Verbal Leaming and Verbal Behavior. in press.

Tulving. E. Episodic and semantic memory. In E. Tulving \& W. Donaldson (Eds.), Organization of memory. New York: Academic Press. 1972.

Winer. B. J. Statistical principles in experimental design. New York: McGraw-Hill. 1971.
(Received for publication January 3, 1977; revision accepted September 6, 1977.) 